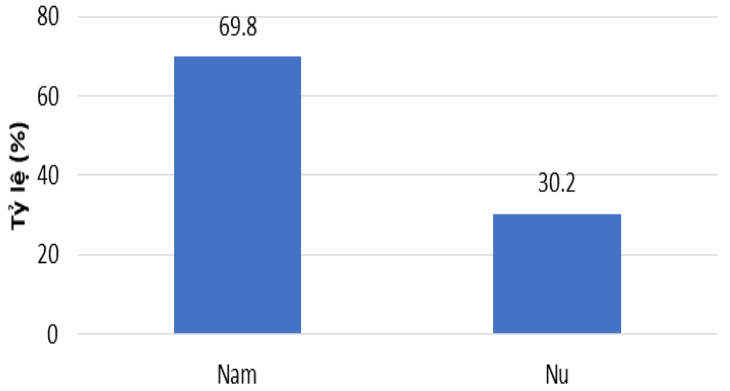

Biểu đồ 2. Phân bố giới tính của người bệnh ung thu

Nhận xét: Phân bố ung thư chủ yễu ở nam $(69,8 \%)$ so với nữ $(30,2 \%)$.

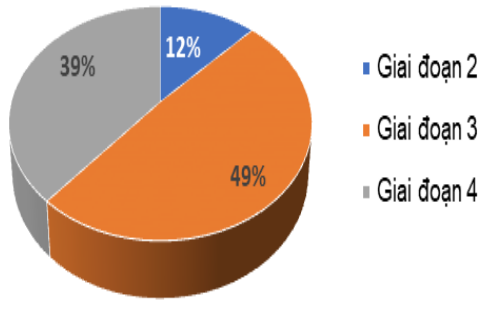

Biểu đồ 3. Phân bố giai đoạn ung thư

Nhận xét: Phần lớn người bệnh ung thư ở giai đoạn $3(49 \%)$ và giai đoạn $4(39 \%)$, giai đoạn 2 chiếm tỷ lệ thấp nhất (12\%).

3.2. Đặc điểm khẩu phân ăn của bệnh nhân ung thư

Nhận xét: So sánh tỷ lệ suy dinh dưỡng qua các phương pháp đánh giá tình trạng dinh dưỡng người bệnh ung thư dựa trên lâm sàng và cận lâm sàng cho thấy: tỷ lệ cao nhất khi đánh giá bằng phương pháp PG-SGA (91\%); sau đó đến các phương pháp đánh giá BMI $(34,4 \%)$, Lympho $(27,8 \%)$, Hemoglobin (25,9\%); tỷ lệ thấp nhất là đánh giá qua Albumin huyết thanh $(6,1 \%)$.

3.3. Giá trị dinh dưỡng khẩu phân ăn của người bệnh ung thư tại bệnh viện

Bảng 3.1. Giá trị năng lượng khẩu phân ăn trung bình cửa bệnh nhần ung thư

\begin{tabular}{|c|c|c|c|}
\hline Nhóm BN & $\begin{array}{c}\text { E KPA } \\
\text { TB } \pm \oplus L C(\text { Kcal/24h) }\end{array}$ & $\begin{array}{c}\text { NCKN } \\
\text { TB } \pm \oplus L C(\text { Kcal/24h) }\end{array}$ & $\begin{array}{l}\text { Tỷ lệ bệnh nhân } \\
\text { đạt NĆKN (\%) }\end{array}$ \\
\hline Ung thư đường tiêu hóa & $1,499.8 \pm 344.9$ & $1,835.6 \pm 249.9$ & $16.40 \%$ \\
\hline Ung thư phối & $1,594.5 \pm 414.6$ & $1,882.9 \pm 229.7$ & $21.40 \%$ \\
\hline Ung & $1,532.7 \pm 306.6$ & $1,739.7 \pm 178.0$ & $36.80 \%$ \\
\hline Ung thư khác & $1,754.6 \pm 448.1$ & $1,857.7 \pm 287.5$ & $32.90 \%$ \\
\hline Chung & $1,627.7 \pm 416.1$ & $1,848.0 \pm 256.2$ & $25.90 \%$ \\
\hline
\end{tabular}

Nhận xét: Trên thực tế, giá trị năng lượng trung bình từ KPA hàng ngày của BN K $(1,627.7 \mathrm{Kcal})$ thấp hơn so với nhu cầu khuyến nghị trung bình $(1,848.0 \mathrm{Kcal})$. Tỷ lệ đạt nhu cầu năng lượng khuyến nghị cho BN K chỉ đạt 25,9\%. Trong đó đạt cao nhất là nhóm ung thư vú $(32.90 \%)$, và thấp nhất là ung thư tiêu hóa (16.40\%).

Bảng 3.2. Giá trị protein khẩu phần ăn trung bình của bệnh nhân ung thư khi điều trị

\begin{tabular}{|c|c|c|c|}
\hline Nhóm BN & $\begin{array}{c}\text { P KPA } \\
\text { TB } \pm \text { KLC }(\mathrm{g} / 24 \mathrm{~h})\end{array}$ & $\begin{array}{c}\text { NCKN } \\
\text { TB } \pm \text { ĐLC }(\mathrm{g} / 24 \mathrm{~h})\end{array}$ & $\begin{array}{c}\text { Tỷ lệ bệnh nhân } \\
\text { đat NCKN }(\%)\end{array}$ \\
\hline Ung the & \pm 14.4 & $64.6 \pm 11.1$ & $34.50 \%$ \\
\hline Ung thư phối & $60.3 \pm 13.8$ & $63.9 \pm 10.3$ & $41.10 \%$ \\
\hline
\end{tabular}




\begin{tabular}{|c|c|c|c|}
\hline Ung thư vú & $60.8 \pm 11.5$ & $61.9 \pm 7.3$ & $57.90 \%$ \\
\hline Ung thư khác & $66.4 \pm 19.1$ & $62.2 \pm 11.6$ & $54.90 \%$ \\
\hline Chung & $62.5 \pm 16.2$ & $63.3 \pm 10.8$ & $46.20 \%$ \\
\hline
\end{tabular}

Nhận xét: Lượng protein trung bình từ KPA hàng ngày của BN K $(62,5 \mathrm{~g})$ thấp hơn so với nhu câu khuyến nghị trung bình $(63,3 \mathrm{~g})$. Tỷ lệ đạt nhu câu lượng protein khuyến nghị cho BN $\mathrm{K}$ chỉ đạt $46,2 \%$. Trong đó đạt cao nhất là nhóm ung thư vú $(57.90 \%)$, và thấp nhất là ung thư tiêu hóa $(34.50 \%)$.

3.6. Yếu tố liên quan đến khẩu phân ăn của người bệnh ung thư

Bảng 3.3. Mối liến quan giữa nhóm tuổi với năng lượng khâu phân ăn $24 h$

\begin{tabular}{|c|c|c|c|c|c|c|c|c|c|}
\hline \multirow{3}{*}{ Nhóm tuổi } & \multicolumn{6}{|c|}{ Năng lượng khấu phân ăn 24h } & \multirow{3}{*}{ OR } & \multirow{3}{*}{$\begin{array}{c}95 \% \\
\text { CI }\end{array}$} & \multirow{3}{*}{$\mathbf{p}$} \\
\hline & \multicolumn{2}{|c|}{ Không đạt NCKN } & \multicolumn{2}{|c|}{ Đạt NCKN } & \multicolumn{2}{|c|}{ Tống } & & & \\
\hline & $\mathbf{S L}$ & $\%$ & SL & $\%$ & $\mathbf{S L}$ & $\%$ & & & \\
\hline$<60$ tuối & 72 & 81.8 & 16 & 18.2 & 88 & 100.0 & & & \\
\hline$\geq 60$ tuối & 85 & 68.5 & 39 & 31.5 & 124 & 100.0 & 2,06 & 399 & $\begin{array}{l}<0,0 \\
5 *\end{array}$ \\
\hline Tống & 157 & 74.1 & 55 & 25.9 & 212 & 100.0 & & & \\
\hline
\end{tabular}

*Kiếm định Pearson Chi-Square

Nhận xét: Tỷ lệ người bệnh có năng lượng khẩu phân ăn 24h không đạt NCKN ở nhóm tuổi < 60 tuổi cao hơn 2,06 lẩn so với nhóm tuổi $\geq 60$ tuổi, sự khác biệt có ý nghĩa thống kê với $p<0,05$.

Bảng 3.4. Môii liên quan giữa nhóm tuổi với lượng protein khẩu phần ăn $24 h$

\begin{tabular}{|c|c|c|c|c|c|c|c|c|c|}
\hline \multirow{3}{*}{$\begin{array}{c}\text { Nhóm } \\
\text { tuổi }\end{array}$} & \multicolumn{6}{|c|}{ Protein khẩu phân ăn 24h } & \multirow{3}{*}{ OR } & \multirow{3}{*}{ 95\% CI } & \multirow{3}{*}{ p } \\
\hline & \multicolumn{2}{|c|}{ Không đạt NCKN } & \multicolumn{2}{|c|}{ Đat NCKN } & \multicolumn{2}{|c|}{ Tổng } & & & \\
\hline & SL & $\%$ & SL & $\%$ & SL & $\%$ & & & \\
\hline$<60$ tuối & 47 & 53.4 & 41 & 46.6 & 88 & 100.0 & & & \\
\hline$\geq 60$ tuối & 67 & 54.0 & 57 & 46.0 & 124 & 100.0 & 0,97 & 168 & $>0,05^{*}$ \\
\hline Tống & 114 & 53.8 & 98 & 46.2 & 212 & 100.0 & & & \\
\hline
\end{tabular}

*Kiếm định Pearson Chi-Square

Nhân xét: Tỷ lệ người bệnh có lượng Protein khẩu phân ăn 24h không đạt NCKN ở nhóm tuổi < 60 tuổi thấp hơn 0,97 lân so với nhóm tuổi $\geq 60$ tuổi, sự khác biệt không có ý nghĩa thống kê với $p>0,05$.

Bảng 3.5. Môi liên quan giữa giới tính với năng lượng khẩu phàn ăn 24h

\begin{tabular}{|c|c|c|c|c|c|c|c|c|c|}
\hline \multirow{3}{*}{$\begin{array}{l}\text { Giới } \\
\text { tính }\end{array}$} & \multicolumn{6}{|c|}{ Năng lượng khấu phân ăn 24h } & \multirow{3}{*}{ OR } & \multirow{3}{*}{$\begin{array}{c}95 \% \\
\text { CI }\end{array}$} & \multirow{3}{*}{$\mathbf{p}$} \\
\hline & \multicolumn{2}{|c|}{ Không đạt NCKN } & \multicolumn{2}{|c|}{ Đạt NCKN } & \multicolumn{2}{|c|}{ Tống } & & & \\
\hline & SL & $\%$ & SL & $\%$ & SL & $\%$ & & & \\
\hline Nam & 116 & 78.4 & 32 & 21.6 & 116 & 100.0 & & & \\
\hline Nũ & 41 & 64.1 & 23 & 35.9 & 41 & 100.0 & 2,03 & $\begin{array}{l}1,07- \\
2,87\end{array}$ & $<0,05^{*}$ \\
\hline Tống & 157 & 74.1 & 55 & 25.9 & 212 & 100.0 & & & \\
\hline
\end{tabular}

* Kiểm định Pearson Chi-Square

Nhận xét: Tỷ lệ người bệnh có năng lượng khẩu phân ăn 24h không đạt NCKN ở nhóm nam giới cao hơn 2,03 lần so với nhóm nữ giới, sự khác biêt có ý nghĩa thống kê với p< $<0,05$.

Bảng 3.6. Mối liên quan giữa giới tính với lượng protein khẩu phân ăn $24 h$

\begin{tabular}{|c|c|c|c|c|c|c|c|c|c|}
\hline \multirow{3}{*}{$\begin{array}{l}\text { Giới } \\
\text { tính }\end{array}$} & \multicolumn{6}{|c|}{ Protein khấu phân ăn $\mathbf{2 4 h}$} & \multirow{3}{*}{ OR } & \multirow{3}{*}{$\begin{array}{c}95 \% \\
\text { CI }\end{array}$} & \multirow{3}{*}{$\mathbf{p}$} \\
\hline & \multicolumn{2}{|c|}{ Không đạt NCKN } & \multicolumn{2}{|c|}{ Đạt NCKN } & \multicolumn{2}{|c|}{ Tống } & & & \\
\hline & $\mathbf{S L}$ & $\%$ & SL & $\%$ & $\mathbf{S L}$ & $\%$ & & & \\
\hline Nam & 88 & 59.5 & 60 & 88 & 59.5 & 100.0 & \multirow{3}{*}{2,14} & \multirow{3}{*}{$\begin{array}{c}1,18- \\
3,89\end{array}$} & \multirow{3}{*}{$<0,05^{*}$} \\
\hline Nữ & 26 & 40.6 & 38 & 59.4 & 26 & 100.0 & & & \\
\hline Tống & 114 & 53.8 & 98 & 46.2 & 212 & 100.0 & & & \\
\hline
\end{tabular}

* Kiếm định Pearson Chi-Square

Nhận xét: Tỷ lệ người bệnh có lượng Protein khẩu phân ăn 24h không đạt NCKN ở nhóm nam giới cao hơn 2,14 lần so với nhóm nữ giới, sự khác biệt có ý nghĩa thống kê với $\mathrm{p}<0,05$.

Bảng 3.7. Mối liên quan giữa giai đoạn bệnh với năng lượng khẩu phân ăn 24h

\begin{tabular}{|c|c|c|c|c|c|c|c|c|c|}
\hline \multirow{3}{*}{$\begin{array}{c}\text { Giai đoạn } \\
\text { bệnh K }\end{array}$} & \multicolumn{6}{|c|}{ Năng lượng khấu phân ăn 24h } & \multirow{3}{*}{ OR } & \multirow{3}{*}{$\begin{array}{c}95 \% \\
\text { CI }\end{array}$} & \multirow{3}{*}{$\mathbf{p}$} \\
\hline & \multicolumn{2}{|c|}{ Không đạt NCKN } & \multicolumn{2}{|c|}{ Đạt NCKN } & \multicolumn{2}{|c|}{ Tống } & & & \\
\hline & $\mathbf{S L}$ & $\%$ & $\mathbf{S L}$ & $\%$ & $\mathbf{S L}$ & $\%$ & & & \\
\hline I-II & 16 & 61.5 & 10 & 38.5 & 26 & 100.0 & 0,51 & $0,21-$ & $>0,05^{*}$ \\
\hline
\end{tabular}


VIETNAM MEDICAL JOURNAL N01 - JUNE - 2021

\begin{tabular}{|c|l|l|l|l|l|l|l|l|l|}
\hline III-IV & 141 & 75.8 & 45 & 24.2 & 186 & 100.0 & & 1,20 & \\
\hline Tổng & 157 & 74.1 & 55 & 25.9 & 212 & 100.0 & & & \\
\hline
\end{tabular}

*Kiểm định Pearson Chi-Square

Nhân xét: Tỷ lệ người bệnh có năng lượng khẩu phần ăn 24h không đạt NCKN ở nhóm K giai đoạn I-II thấp hơn 0,51 lần so với nhóm K giai đoạn III-IV, sự khác biệt không có ý nghĩa thống kê với $p>0,05$.

Bảng 3.8. Môi liên quan giữa giai đoan bênh với lượng protein khẩu phän ăn 24h

\begin{tabular}{|c|c|c|c|c|c|c|c|c|c|}
\hline \multirow{3}{*}{$\begin{array}{c}\text { Giai đoạn } \\
\text { bệnh K }\end{array}$} & \multicolumn{6}{|c|}{ Protein khấu phần ăn $24 \mathrm{~h}$} & \multirow{3}{*}{ OR } & \multirow{3}{*}{$\begin{array}{c}95 \% \\
\text { CI }\end{array}$} & \multirow{3}{*}{ p } \\
\hline & \multicolumn{2}{|c|}{ Không đạt NCKN } & \multicolumn{2}{|c|}{ Đạt NCKN } & \multicolumn{2}{|c|}{ Tống } & & & \\
\hline & $\mathbf{S L}$ & $\%$ & SL & $\%$ & $\mathbf{S L}$ & $\%$ & & & \\
\hline I-II & 10 & 38.5 & 16 & 61.5 & 26 & 100.0 & \multirow{3}{*}{0,49} & \multirow{3}{*}{$\begin{array}{c}0,21- \\
1,14\end{array}$} & \multirow{3}{*}{$>0,05^{*}$} \\
\hline III-IV & 104 & 55.9 & 82 & 44.1 & 186 & 100.0 & & & \\
\hline Tống & 114 & 53.8 & 98 & 46.2 & 212 & 100.0 & & & \\
\hline
\end{tabular}

*: Kiểm định Pearson Chi-Square

Nhận xét: Tỷ lệ người bệnh có lượng Protein khẩu phần ăn 24h không đạt NCKN ở nhóm K giai đoạn I-II thấp hơn 0,49 lần so với nhóm K giai đoạn III-IV, sự khác biệt không có ý nghĩa thống kê với $p>0,05$.

\section{BÀN LUÂN}

4.1. Tình trạng dinh dưỡng của bệnh nhân ung thư. Phân loại theo phương pháp PGSGA cho người bệnh ung thư cho thấy tỷ lệ người bệnh có nguy cơ SDD hay SDD vừa/nặng (SGA B và $C)(91,0 \%)$ cao hơn tỷ lệ người bểnh có tình trạng dinh dưỡng tốt $(9,0 \%)$, trong đó tỷ lệ người bệnh có nguy cơ SDD nặng chiếm tỷ lệ cao nhất. Như vậy suy dinh dưỡng rất phổ biến đối với người bệnh ung thư [3]. Kết quả đánh giá tình trạng dinh dưỡng bằng phương pháp PG - SGA cho thấy cần phải có kế hoạch sàng lọc đánh giá và đánh giá lại định kỳ TTDD của tất cả người bệnh nhập viện ngay từ sớm để có biện pháp can thiệp phù hợp, đặc biệt là người bệnh có nguy cơ SDD cao như người bệnh ung thư [5].

Có sự khác biệt về tình trạng dinh dưỡng giữa người bệnh nam và nữ mắc ung thư theo đánh giá BMI song sự khác biệt này chưa có ý nghĩa thống kê với $p>0,05$. So sánh phương pháp đánh giá tình trạng dinh dưỡng theo $B M I$ và $P G$ - SGA thì tỷ lệ người bệnh bị SDD theo BMI $(27,3 \%)$ thấp hơn nhiều so với tỷ lệ người bệnh có nguy cơ SDD và SDD theo PG - SGA $(91,0 \%)$. Điều này cho thây nếu chỉ đánh giá TTDD người bệnh chỉ bằng chỉ số nhân trắc mà không lượng giá tình trạng sưt cân, thay đổi khẩu phần ăn hay các chỉ số thăm khám lâm sàng thì sẽ khó dự đoán người bệnh đã có dấu hiệu tiền suy mòn hay đã rơi vào giai đoạn suy mòn, ngay cả ở người bệnh có BMI trong giới hạn bình thường hay thừa cân, dẫn đến bỏ sót rất nhiều người bệnh có nguy cớ SDD [1]. Điều này có thể do PG-SGA đánh giá kỹ khối cơ và thay đổi khối cơ liên quan đến chức năng hoạt động của người bệnh nên đã phát hiện được nhiều trường hợp bị suy dinh dưỡng bị bỏ sót khi đánh giá bằng BMI [2].

4.2. Một số yếu tố liên quan đến tình trạng dinh dưỡng của người bệnh

- Nhóm tuổi: Tuổi càng cao thì nguy cơ SDD càng tăng. Theo phân loại SGA, ở nhóm tuổi $\geq$ 60 tuổi người bệnh có nguy cơ SDD cao gấp 2,07 lần ở nhóm tuổi $<60$ tuổi $(p>0,05)$. Tuy nhiên khi phân tích năng lượng khẩu phần ăn 24h không đạt NCKN ở nhóm tuổi $<60$ tuổi $(81,8 \%)$ cao hơn so với ở nhóm tuổi $\geq 60$ tuổi $(68,5 \%)$. Điều này có thể lý giải, ở nhóm tuổi càng cao thì cân nặng có xu hướng giảm nên nhu cầu năng lượng giảm, cùng khẩu phần ăn gần như nhau về năng lượng thì tỷ lệ đạt so với nhu cầu của người $>60$ tuổi sẽ cao hớn nhóm $<60$ tuổi. Dẫn đến kết quả nhóm tuổi có mối liên quan với phân loại SGA và năng lượng khẩu phần ăn 24h [6].

- Giới tính: Tỷ lệ người bệnh có năng lượng khẩu phần ăn 24h không đạt NCKN ở nhóm nam giới cao hơn 2,03 lần so với nhóm nữ giới, sự khác biệt có ý nghĩa thống kê với $p<0,05$. Tỷ lể người bệnh có lượng Protein khẩu phần ăn $24 \mathrm{~h}$ không đạt NCKN ở nhóm nam giới cao hơn 2,14 lần so với nhóm nữ giới, sự khác biệt có ý nghĩa thống kê với $p<0,05$. Lý giải có thể do nữ giới để ý ăn uống hơn nam giới và chịu khó tuân thủ các hướng dẩn dinh dưỡng cho điều trị bệnh, cũng có thể do cơ cấu mắc ung thư của nam giới khác nữ giới [6].

- Giai đoạn bệnh: Số người bệnh phát hiện bệnh ở người bệnh ung thư ở giai đoạn 3 (49\%) và giai đoạn $4(39 \%)$, giai đoạn 2 chiếm tỷ lệ thấp nhất (12\%). Tỷ lệ người bệnh có năng lượng khẩu phần ăn 24h không đạt NCKN ở nhóm $\mathrm{K}$ giai đoạn I-II thấp hơn 0,51 lần so với nhóm K giai đoạn III-IV ( $p>0,05$.). Tỷ lệ người 
bệnh ung thư có nguy cơ SDD phổ biến ở giai đoạn tiến triển, phù hợp với nghiên cứu của Torre (2015) [6].

- Vị trí khối u: Tỷ lê suy dinh dưỡng năng (SGA C) cao nhất ở nhóm $K$ đường tiêu hóa $(58,2 \%)$, sau đó đến $K$ phổi $(51,8 \%)$ và thấp nhất là $K$ vú $(36,8 \%)$. Như vậy, tỷ lệ SDD ở nhóm ung thư phổi; ung thư đường tiêu hóa cao hơn các nhóm còn lại, sự khác biệt có ý nghĩa thống kê với $p<0,05$. Kết quả này tương tự như nghiên cứu của Datema (2011), theo đó tỷ lê SDD ở nhóm người bênh ung thư đầu, mặt, cổ cao hơn các nhóm còn lại [4].

\section{KẾT LUẬN}

Qua nghiên cứu thực trạng cho thấy tình trạng SDD trên người bệnh ung thư bằng các phương pháp khác nhau cho thấy SDD phổ biến ở người bị ung thư. Năng lượng khẩu phần ăn đạt nhu cầu khuyến nghị chiếm tỷ lệ thấp. Các đặc điểm thay đổi chế độ ăn thường gặp là: giảm khẩu phần ăn, chỉ ăn được thực phẩm lỏng hoặc ăn rất ít. Phân tích rút ra một số yếu tố liên quan đến giá trị khẩu phần ăn đạt nhu cầu khuyến nghị của người bệnh ung thư: giữa nhóm tuổi (<60 tuổi; >=60 tuổi) với năng lượng khẩu phần ăn 24h $(O R=2,06 ; p<0,05)$, giữa giới tính (nam; nữ) với năng lượng khẩu phần ăn $24 \mathrm{~h}$ $(\mathrm{OR}=2,03 ; \mathrm{p}<0,05)$ và lượng Protein khẩu phần ăn 24h $(\mathrm{OR}=2,14 ; \mathrm{p}<0,05)$, không có liên quan giữa giai đoạn ung thư với năng lượng khẩu phần ăn $24 h(O R=0,51 ; p>0,05)$.

\section{TÀI LIÊU THAM KHẢO}

1. Andreoli, A., De Lorenzo A, Cadeddu $F$ et al, New trends in nutritional status assessment of cancer patients. Eur Rev Med Pharmacol Sci, 2011. 15(5): p. 469-480.

2. Aoyagi, T., Terracina K.P, Raza A et al, Cancer cachexia, mechanism and treatment. World journal of gastrointestinal oncology, 2015. 7(4): p. 17.

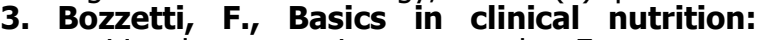
nutritional support in cancer. the European eJournal of Clinical Nutrition and Metabolism, 2010. 5(3): p. 148-152.

4. Datema, F.R., Ferrier M.B and Baatenburg de Jong RJ., Impact of severe malnutrition on shortterm mortality and overall survival in head and neck cancer. Oral oncology, 2011. 47(9): p. 910-914.

5. Pressoir, M., Desné S, Berchery D et al, Prevalence, risk factors and clinical implications of malnutrition in French Comprehensive Cancer Centres. British journal of cancer, 2010. 102(6): p. 966.

6. Torre, L.A., Bray F, Siegel R.L et al, Global cancer statistics, 2012. a cancer journal for clinicians, 2015. 65(2): p. 87-108.

\title{
HIỆU LỰC VÀ Độ TIN CÂYY CỦA THANG ĐO RỐI LOẠN CĂNG THẲNG SAU SANG CHẤN (PSS-SR) TRÊN SINH VIÊN NĂM CUỐI TRƯỜNG ĐẠI HỌC Y HÀ NộI TRONG ĐẠI DỊCH COVID-19
}

\author{
Phạm Anh Tùng ${ }^{1}$, Trần Thị Len ${ }^{2}$, Bùi Thanh Thúy ${ }^{1}$, Trần Tho Nhị ${ }^{3}$, \\ Nguyễn Minh Sang ${ }^{4}$, Trần Thị Thanh Hương ${ }^{3,5}$, Đỗ Tuyết Mai ${ }^{5}$
}

\section{TÓM TẮT}

Mục tiêu: Nghiên cứu này đã khảo sát khả năng sử dụng bộ câu hỏi đánh giá rối loạn căng thẳng sau sang chấn phiên bản tiếng Việt trên sinh viên năm cuối trường Đại học Y Hà Nội trong thời điểm đại dịch COVID-19 từ tháng 3 đến tháng 5 năm 2020. Đối tượng và phương pháp: Nghiên cứu cắt ngang sử dụng thang đo đánh giá rối loạn căng thẳng sau sang chân phiên bản tự báo cáo (PŚS-SR) trên 68 sinh viên

\footnotetext{
${ }^{1}$ Viện Vệ sinh Dịch tễ Trung Uơng

${ }^{2}$ Bệnh viện Phụ sản Trung Ương

${ }^{3}$ Đai hoc Y Hà Nôi

${ }^{4}$ Đai học Vanderbilt

5 Viện Ung thư Quốc gia. Bệnh viện K

Chịu trách nhiệm chính: Phạm Anh Tùng

Email: patung.yhdp.hmu@gmail.com

Ngày nhận bài: 9.3.2021

Ngày phản biên khoa học: 10.5.2021

Ngày duyệt bài: 17.5.2021
}

năm thứ 6 đang theo học tại trường Đại học $Y$ Hà Nội năm 2020. Nhóm nghiên cứu sử dung mô hình CFA và kiểm định độ tin cậy để đánh giá hiệu lực và độ tin cậy của bộ câuu hỏi. Kết quả: Theo kểt quả kiểm định đồ tin cậy, các câu hỏi của thang đo PSS-SR đều có hể số Cronbach Alpha chấp nhận được về mặt tin cậy (lớn hơn mức yêu cầu 0,6 ). Xét hệ số tương quan biển - tổng (hiệu chỉnh) của các biến quan sát đều đạt yêu câu $>0,30$. Kiểm định CFA cho thấy mô hình có 116 bậc tự do, giá trị kiểm định chi-square $=235,914$ với $\mathrm{p}<0,005$ và các chỉ số chỉ ra mô hình phù hợp với dữ liệu (CFI =0,808; RMSEA =0,124; SRMR=0,08). Cả 3 thành phần đều đat được tính đơn hướng. Kết luận: Đề tài nghiên cứu đã kiểm định bản tiếng Việt của bộ câu hỏi đánh giá rối loạn căng thẳng sau sang chấn phiên bản tiếng Việt với 17 câu hỏi đánh giá 3 thành phần: (1) Nhớ lại, (2) Kích thích, (3) Lảng tránh.

Tư khóa: Rối loạn căng thẳng sau sang chấn, PSS-SR

\section{SUMMARY \\ VALIDITY AND RELIABILITY OF THE POST-}

